\title{
SOME PROPERTIES OF A FUNCTION CONNECTING TO EXPONENT OF CONVERGENCE FOR DOUBLE SEQUENCES
}

\author{
D. K. Ganguly, B. Biswas and Alauddin Dafadar
}

Abstract. In this paper, we extend the notion of exponent of convergence for double sequences and study some properties of a function connecting with a non-decreasing double sequence in a Fréchet metric space.

Mathematics subject classification (2010): 40A05.

Keywords and phrases: Baire and Borel classification of sets, category of sets, measurable function, exponent of convergence, double sequences.

\section{REFERENCES}

[1] D. K. Ganguly, A. Dafadar, B. Biswas, On Some Properties of a Function Connecting with an infinite Series, Acta. Math. Univ. Comenianae, LXXIX, 2 (2010), 217-223.

[2] D. K. Ganguly, B. Biswas, A function on exponential convergence in a Fréchet metric space, Extracta Mathematicae, 28, 1 (2013), 49-56.

[3] T. J. BRomwich, An Introduction to the Theory of Infinite Series, Macmillan and Co. Ltd., New York, (1965).

[4] G. Pólya und G. Szegő, Aufgaben und Lehrsatze Aus Der Analysis, Springer-Verlag, Berlin, Göttingen, Heidelberg, New York, (1964).

[5] P. Kostyrko and T. ŠAÁt, On the exponent of convergence, Rend. Circ. Mat. Palermo Ser. II Tomo, XXXI, (1982), 187-194.

[6] A. Pringsheim, Zur theorie der zweifach unendlichen zahlenfolgen, Mathematische Annalen, 53, 3 (1900), 289-321, MR 1511092.

[7] G. H. Hardy, On the convergence of certain multiple series, Proc. London Math. Soc., 19 s2-1, 1 (1904), 124-128, MR 1576764.

[8] G. M. Robison, Divergent Double Sequences and Series, Amer. Math. Soc. Trans. 28, 1 (1926), 50-73, MR 1501332.

[9] H. J. Hamilton, Transformations of Multiple Sequences, Duke Math. Jour. 2 (1936), 29-60.

[10] G. G. Lorentz, A contribution to theory of divergent sequences, Acta. Math., 80 (1948), 167-190.

[11] D. K. Ganguly, C. Dutta, Some properties of a function connected to a double series, Bull. Malayasian Math. Sc. Soc. 24 (2001), 177-181.

[12] K. KuRAtowski, Topology, Volume I, Academic Press, (1958). 